\title{
The role of microsomal oxidation in the regulation of monoamine oxidase activity in the brain and liver of rats
}

\author{
Denis A. Kozochkin ${ }^{1} \uparrow$, Eugenia B. Manukhina ${ }^{1,2,3}$, H. Fred Downey ${ }^{2}$, Olga B. Tseilikman ${ }^{1}$, \\ Maria V. Komelkova ${ }^{1}$, Maria V. Vasilyeva ${ }^{1}$, Maxim S. Lapshin ${ }^{1}$, Marat N. Sahabutdinov ${ }^{4}$, \\ Svetlana S. Lazuko ${ }^{5}$ and Vadim E. Tseilikman ${ }^{1,4}$ \\ ${ }^{1}$ South Ural State University Biomedical School, Chelyabinsk, Russia \\ ${ }^{2}$ University of North Texas Health Science Center, Fort Worth, Texas, USA \\ ${ }^{3}$ Institute of General Pathology and Pathophysiology, Moscow, Russia \\ ${ }^{4}$ South Ural State Medical University, Chelyabinsk, Russia \\ ${ }^{5}$ Vitebsk State Medical University, Vitebsk, Belarus
}

\begin{abstract}
It has been shown in our previous study that monoamine oxidase (MAO) activity in different brain regions are correlated with a microsomal oxidation phenotype. The data obtained in this study, using the microsomal oxidation inhibitor SKF525, and using animals with different duration of hexobarbital sleep, has shown that increased intensity of microsomal oxidation might be associated with increased MAO activity. Since the rats with short hexobarbital sleep time had higher content of hepatic microsomal cytochrome P450 than did rats with long hexobarbital sleep time. In addition, the rats with higher hepatic content of CYP450 had higher activities of MAO-A and MAO-B. Moreover, the microsomal oxidation inhibitor SKF525 reduced brain and liver activities of MAO-A and MAO-B. Consequently, MAO activities in a brain and a liver depend on the microsomal oxidation process.
\end{abstract}

Key words: Microsomal oxidation - Monoamine oxidase - SKF525 - CYP450 - Hexobarbital sleep time

\section{Introduction}

Monoamine oxidase (MAO) is bound to the outer membrane of mitochondria and plays a key role in intracellular metabolism of phenyl- and indolalkylamines (Nagatsu 2004). There are two types of MAO, namely: MAO-A and MAO-B, which differ in their sensitivity to the acetylene inhibitors, clorgyline, pargyline, and deprenyl, substrate specificity, and their dependence on the lipid microenvironment (Chen and Shih 1998). MAO-A preferentially deaminates norepinephrine and serotonin and loses its activity upon depletion of mitochondrial phospholipids (Ekstedt and Oreland 1976). O-phenylethylamine and dopamine are specific substrates for MAO-B (Glover et al. 1977; Kwan 2001). The major physiological function of MAOs is involvement in metabolism of monoamine neurotransmitters.

Correspondence to: Vadim Tseilikman, South Ural State Medical University, Chelyabinsk, Russia

E-mail: vadimed@yandex.ru
Changes in the rate of biogenic amine deamination in nerve tissue play a significant role in the pathogenesis of mood and behavioral disorders (Brunner et al. 1993; Furlong et al. 1999). Severity of depressive disorders correlates with increased brain MAO activity and decreased brain levels of serotonin and norepinephrine (Tipton et al. 1992; Miura et al. 1993). A low level of brain MAO is a marker of alcoholism (Oreland 2004).

It is known that MAO contributes to oxidative stress, since hydrogen peroxide $\left(\mathrm{H}_{2} \mathrm{O}_{2}\right)$ is a co-product of the $\mathrm{MAO}$ reaction. Therefore, $\mathrm{MAO}$ inhibitors exert antioxidant effects. Hepatic CYP450 isoforms degrade MAO inhibitors, thereby increasing the activity of MAOs (Spina et al. 2012). CYP450 isoforms participate in metabolism of glucocorticoids (Quattrochi et al. 2001). Corticosterone is an important regulator of MAO-A and MAO-B expression and activity (Duncan et al. 2012). Also, CYP450 isoforms are important for corticosterone tissue metabolism (Quattrochi and Guzelian 2001). During stress, glucocorticoids regulate 
expression and activity of MAO-A and MAO-B (Grunewald et al. 2012). However, the relationship between brain MAO activity and intensity of hepatic CYP450 microsomal oxidation has not been studied previously.

This study focuses on a potential role of hepatic CYP450 microsomal oxidation in regulation of MAO-dependent processes in the brain. Since MAO is important for the regulation of oxidative stress, we compared MAO activities with concentrations of lipid peroxidation products and carbonylated proteins in the brain and liver of rats with different activities of CYP450 hepatic microsomal oxidation.

\section{Materials and Methods}

\section{Chemicals}

Hexobarbital and Selegiline were purchased from SigmaAldrich, Inc. (St-Louis, MO, USA); Clorgyline was purchased from Sigma (Basel, Switzerland); and SKF525 from Sigma (Saint Quentin Fallavier, France).

\section{Animals}

The study used 117 Sprague-Dawley rats. They were housed in standard rat cages and fed rat chow and tap water ad libitum. The temperature in the housing facility was controlled at $21^{\circ} \mathrm{C}$, and lights were set to a 12:12-h light/dark cycle, with lights on at 7:00 a.m. The rats were provided by the breeding facility "Pushchino" (Pushchino, Russia) and allowed three weeks to acclimatize before the initiation of the study protocol. During this acclimatization period they were handled and weighed once per day (7 times per week) so that they could get accustomed to this procedure. The investigation conformed to the standards set by the "Guide for the Care and Use of Laboratory Animals" published by the National Institutes of Health (NIH publication 85-23, revised in 2011), and the study was approved by the South Ural State Medical University Ethics Review Board.

\section{Hexobarbital sleep time}

We have studied the relationship between microsomal oxidation, as indexed by hexobarbital sleep time (HST) (Coville and Telford 1970; Pappas et al. 1993; Cherala et al. 2007), and MAO activity in brain and liver. Sleep was induced by the hexobarbital, which is barbiturate derivative (Pappas et al. 1993; Lewis et al. 1997). Depending on HST, rats were characterized as fast and slow metabolizers of hexobarbital.

Hexobarbital solution was prepared freshly on the day of the experiment and administered i.p. at a dose of $60 \mathrm{mg} / \mathrm{kg}$. HST was designated as the time between injection and recov- ery of the righting reflex, which was defined as the ability of the animal, when placed on its back on a flat surface, to turn over on its paws three times in $15 \mathrm{~s}$. Based on results of the HST test, rats were divided into rats with short HST duration (SHST, <15 min, fast metabolizers) and long HST duration (LHST, $>15 \mathrm{~min}$, slow metabolizers). Three groups of rats were studied: 1) rats injected with hexobarbital, $60 \mathrm{mg} / \mathrm{kg}$ $(n=23) ; 2)$ rats injected with an equal volume of $0.9 \% \mathrm{NaCl}$ $(n=11) ; 3)$ untreated, intact rats $(n=11)$.

Rats were sacrificed on 14 day of the HST test. As described below, content of CYP450 was measured in hepatic microsomes. Activities of MAO-A and MAO-B were measured in liver and brain mitochondria. Concentrations of lipid peroxidation (LP) products and carbonylated proteins were measured in the liver and brain.

\section{Injections of a microsomal oxidation inhibitor and selective $M A O-A$ and $M A O-B$ inhibitors}

The hypothesis of a relationship between activities of microsomal oxidation and MAO was tested by inhibiting microsomal oxidation with inhibitor SKF525 (Sigma, Saint Quentin Fallavier, France). For chronic inhibition of CYP450-dependent MAOs, rats received SKF525 (25 mg/ $\mathrm{kg}$, i.p.) four times for 12 days with 72 -h intervals between injections $(n=16)$. The rats did not receive SKF525 from day 13 through day 15 . In selecting this dosage, we took into account that the highest tolerated dose of SKF525 is $50 \mathrm{mg} /$ $\mathrm{kg}$ (Choi and Lee 2006).

For chronic inhibition of MAO-A activity, rats were injected with low doses of the MAO-A inhibitor, clorgyline, $1 \mathrm{mg} / \mathrm{kg}$, i.p., daily for 12 days $(n=10)$. For chronic inhibition of MAO-B activity, rats were injected with the MAO-B inhibitor, selegeline, $1 \mathrm{mg} / \mathrm{kg}$, i.p., daily for 12 days $(n=10)$.

\section{Sample collection and treatment}

Rats were sacrificed by inhalation anesthesia with diethyl ether ( $2.75 \mathrm{ml} / \mathrm{l}$ air). For measuring CYP450 content in hepatic microsomes, the liver was isolated and washed in cold $0.9 \% \mathrm{NaCl}$. Samples (500 mg) were prepared and stored in liquid nitrogen. The brain homogenates were used for measuring MAO-A and MAO-B activity, carbonylated proteins, lipid peroxidation products, and serotonin concentration.

\section{Measurement of corticosterone}

Blood was transferred to sterile glass tubes containing $\mathrm{K}_{2}$ EDTA, rotated, and centrifuged at $4^{\circ} \mathrm{C}$ and $8,000 \times g$ for 10 min. Plasma was separated into aliquots, which were frozen at $-80^{\circ} \mathrm{C}$ for batch assays. Corticosterone was measured in duplicate using a commercial RIA kit (Bioclin, Cardiff, UK) in according to the procedure recommended by the manu- 
facturer. The sensitivity of the assay is $0.25 \mathrm{ng} / \mathrm{ml}$ and the intra- and inter-assay coefficients of variation were both $<5 \%$.

\section{Measurement of total CYP content in hepatic microsomes}

Livers were homogenized in $1.15 \% \mathrm{KCl}$. Having centrifuged the homogenates at 9,000 $\times g$ for $20 \mathrm{~min}$, we centrifuged the supernatant at 100,000 $\times g$ for $60 \mathrm{~min}$. Microsomal pellets were resuspended in $0.1 \mathrm{M}$ Tris-HCl buffer ( $\mathrm{pH}$ 7.4) containing $0.5 \mathrm{mM}$ dithiothreitol, $0.1 \mathrm{mM}$ EDTA, and $20 \%$ glycerol. Microsomal protein concentrations were determined by the Bradford protein assay method, using the Bio-Rad Protein Assay kit (Bio-Rad, Hercules, CA, USA) and bovine serum albumin (BSA; Sigma-Aldrich Inc., St. Louis, MI, USA) as the standard, according to the protocol provided by the manufacturer. The total CYP450 (CYP) content was quantified from the carbon monoxide difference spectrum of the dithionite-reduced proteins recorded at 450-490 nm, using an extinction coefficient $91 \mathrm{mM}^{-1} \mathrm{~cm}^{-1}$ as described by Omura and Sato (1964).

\section{Measurement of MAO activities in brain tissue}

The activities of the brain MAO-A and MAO-B were measured as described by Tipton et al. (2006). Before adding specific substrates, brain or liver homogenates were preincubated with a selective, irreversible inhibitor of one of the MAO isoforms for $60 \mathrm{~min}$ at $37^{\circ} \mathrm{C}$. Thus, MAO-A activity was measured in the presence of selegeline, a selective MAO-B inhibitor, and MAO-B activity was measured in the presence of clorgyline, a selective $\mathrm{MAO}-\mathrm{A}$ inhibitor. For inhibition of MAO-A or MAO-B activity, $100 \mu \mathrm{l}$ of $1 \mu \mathrm{M}$ clorgyline or $100 \mu \mathrm{l}$ of $0.5 \mu \mathrm{M}$ selegeline, respectively, was added to $1 \mathrm{ml}$ of mitochondrial suspension containing MAO in the membrane-bound form and incubated for $60 \mathrm{~min}$ at $37^{\circ} \mathrm{C}$. For measuring the MAO-A activity, $4 \mathrm{mM}$ 5-hydroxytriptamine creatinine sulfate was used as a substrate. For measuring the MAO-B activity in the isolate mitochondria $13.32 \mathrm{mM}$ bensylamine hydrochloride was used as a substrate. Brain homogenate was prepared in $0.067 \mathrm{M}$ sodium phosphate buffer (e.g., $1 / 10 \mathrm{w} / \mathrm{v} ; \mathrm{pH}$ 7.2) and centrifuged to isolate the mitochondria. The isolation of rat mitochondria was carried out according to the method reported by Satav and Katyare (2004).

\section{Measurement of lipid peroxidation products}

Five $\mathrm{ml}$ heptane-isopropanol mixture $(1: 1, \mathrm{v} / \mathrm{v})$ was added to $0.5 \mathrm{ml}$ of tissue homogenate suspended in $0.9 \% \mathrm{NaCl}$ containing $0.1 \%$ EDTA. Then the mixture was stirred by shaker for 20 minutes. Then it was purified from the protein precipitate and other corpuscular impurities by centrifugation. The decontaminated solution was diluted with $5 \mathrm{ml}$ of heptane-isopropanol mixture (3:7, v/v) and $2 \mathrm{ml}$ of hydrochloric acid ( $\mathrm{pH} 2)$. Then it was incubated for $30 \mathrm{~min}$ to achieve complete phase separation. The upper (heptane) phase was carefully transferred to another tube. Results were expressed as the oxidation index, $\mathrm{E}_{278 / 220}$ for ketodienes and conjugated trienes (KD+CT) (Volchegorskii et al. 1989).

\section{Measurement of protein oxidation products}

Protein carbonyls were measured using the method described by Levine (1990), which involves using 2,4-dinitrophenylhydrazine as a reagent and estimating the 2,4-dinitrophenylhydrazone derivative content in proteins. The carbonyl content was measured at $430 \mathrm{~nm}$ and expressed as $\mathrm{nmol}$ protein carbonyls per $\mathrm{mg}$ of tissue. Protein concentration was determined according to the Bradford method using the Bio-Rad Protein Assay kit (Bio-Rad, Hercules, CA, USA).

\section{Statistical analyses}

Values were calculated as means \pm standard deviations (S.D.). A Student's $t$-test was used for comparison between the control and SKF525-treated group, clorgyline-treated group, selegeline-treated group. A one-way ANOVA was used for multiple comparisons (e.g. control vs. SHST, control $v s$. LHST, SHST $v s$. LHST). $p$ values less than 0.05 were considered to be significant. Correlations between measured parameters were explored by calculation of Spearman's correlations $(\mathrm{R})$.

\section{Results}

Concentrations of CYP450 in the liver tissue, heptanesoluble ketodienes, conjugated trienes and carbonylated proteins in brain and liver, and MAO-A and MAO-B activities in brain and liver did not significantly differ between rats injected with $0.9 \% \mathrm{NaCl}$ saline and those left non-injected, intact rats. For this reason, results from experimental procedures are compared only with those observed in intact rats, which here after are described as control rats.

\section{Correlation between duration of HST and liver content of CYP450}

HST is considered an index of hepatic microsomal oxidation. After hexobarbital treatment it was shown that the rats can be divided into two groups with short (11.34 \pm $2.07 \mathrm{~min}$ ) and long (38.25 $\pm 11.29 \mathrm{~min})$ HST duration (Fig. $1 \mathrm{~A}, p<0.0001)$. The short HTS group included $47 \%$ and the long HTS group included $53 \%$ of the rats. A one-way ANOVA showed that SHST rats had higher CYP450 levels in compared with control rats as well as in compared with 
LHST rats $\left(\mathrm{F}_{(2,35)}=6.42, p=0.0045\right)$. In the SHST group the liver content of CYP450 (Fig. 1B) was higher by $18 \%$ compared to the control $(p=0.023)$ and by $29 \%$ compared to the LHST group $(p=0.001)$. LHST rats did not show significant differences with control rats $(p=0.31)$. Overall, HST negatively correlated with microsomal CYP450 level $(\mathrm{R}=-0.89 ; p=0.006)$. CYP450 of intact and LHST rats did not significantly differ.
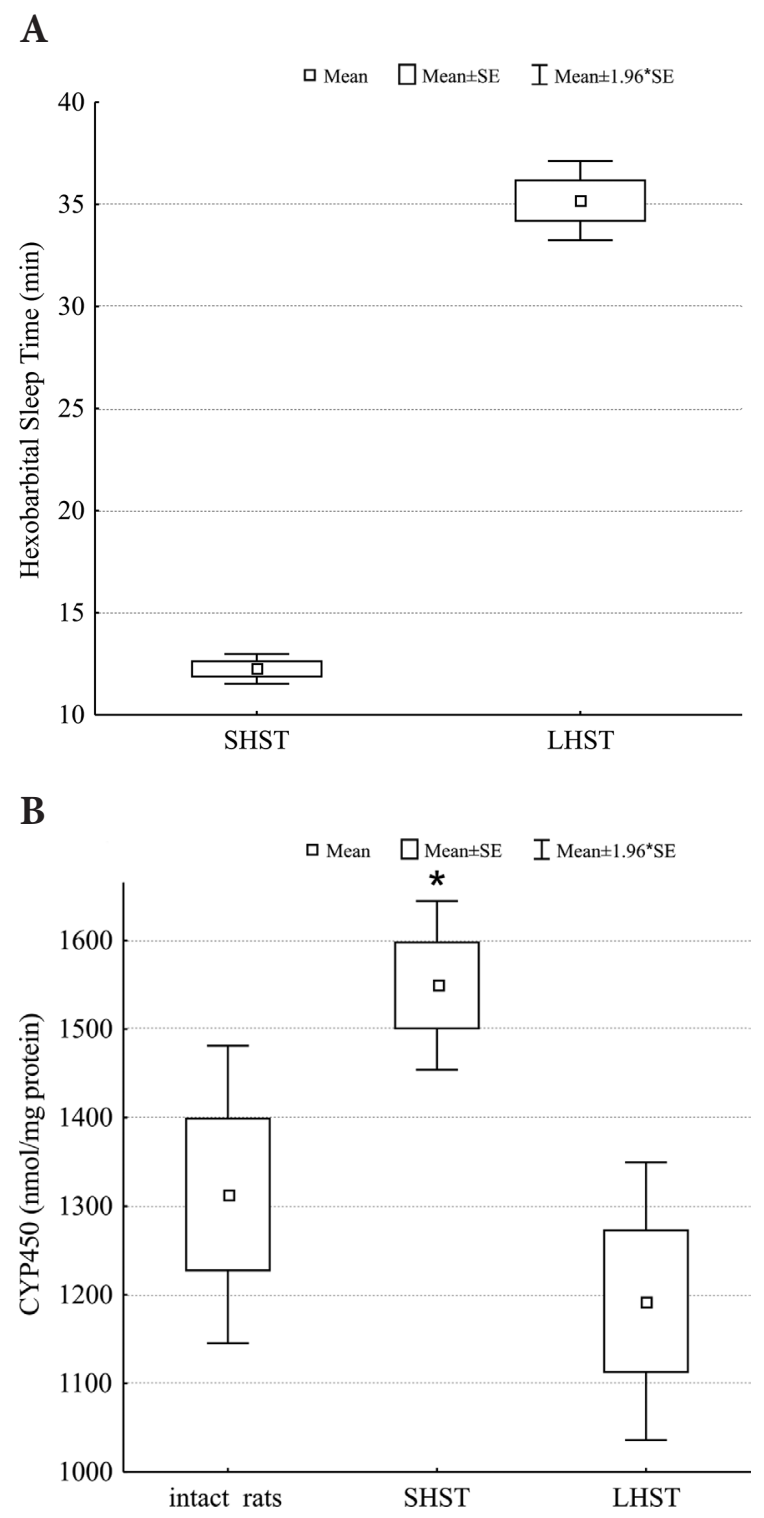

Figure 1. Hexobarbital sleep time (HST) test (A) and concentration of the hepatic CYP450 (B) in untreated rats and the hexobarbital treatment subjected rats. FM, groups with high intensity of microsomal oxidation (HST $<15 \mathrm{~min}$ ); SM, groups with low intensity of microsomal oxidation (HST $>15 \mathrm{~min}$ ); SHST, short sleep group; LHST, long sleep group. ${ }^{\star}$ significant difference from all other groups (intact rats: $p=0.22$; LHST rats: $p=0.007$ ).
A

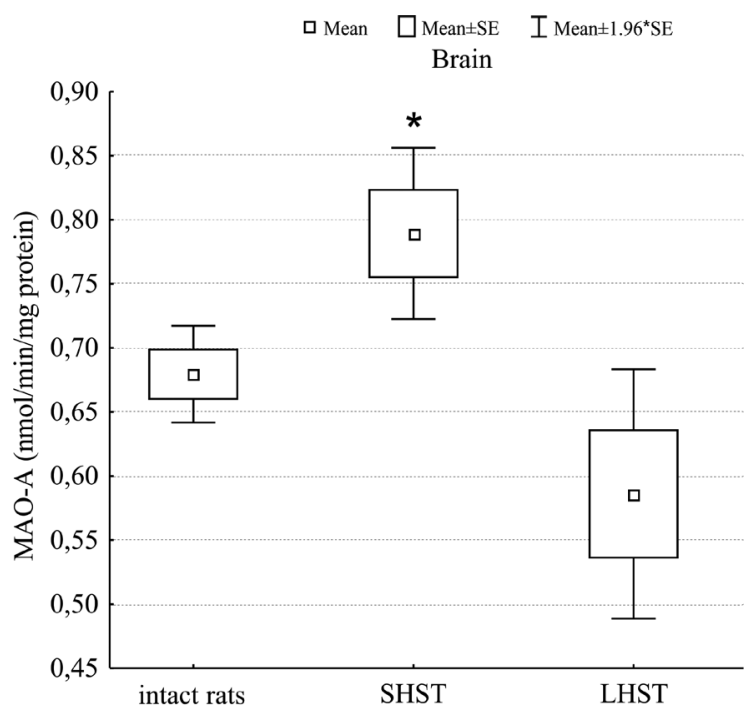

B

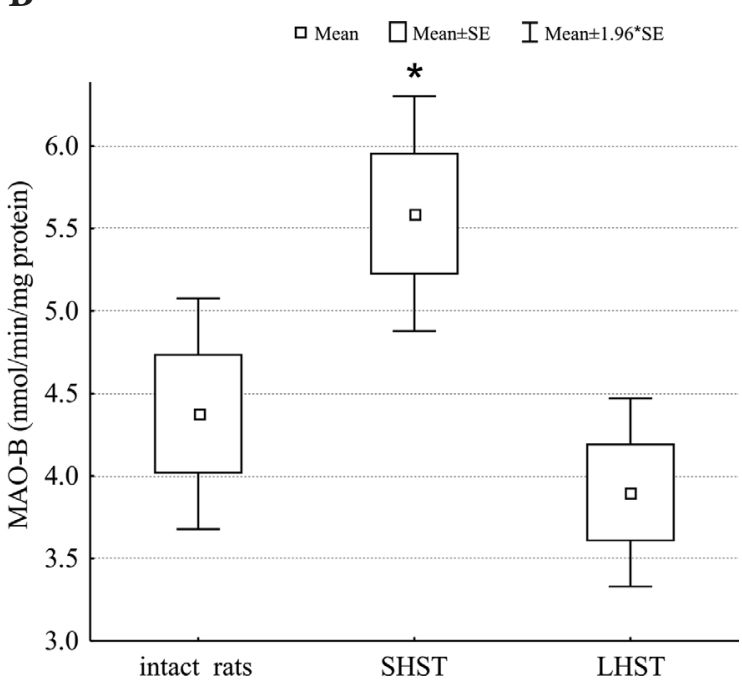

Figure 2. Brain MAOs activity in untreated intact rats and in the hexobarbital treatment subjected rats. A. Brain MAO-A activity was greater in the SHST group than in intact rats $(p=0.019)$ and in the LHST group $(p=0.007)$. B. Brain MAO-B activity was greater in the SHST group than in intact rats $(p=0.027)$ and in the LHST group $(p=0.001) .{ }^{\star}$ significant difference from all other groups.

\section{Correlation between brain $M A O$ activity and hepatic CYP450 in rats with different HST}

Fig. 2A highlights the differences in the brain MAO-A activities of rats with different $\operatorname{HST}\left(\mathrm{F}_{(2,35)}=7.65, p=0.002\right)$. The activity of brain MAO-A (Fig. 2A) of SHST rats was higher than of activity of MAO-A of control rats by $16 \%(p=0.012)$ and also higher than activity of MAO-A of LHST rats by 
$34 \%(p=0.003)$. A one-way ANOVA revealed significant differences in the brain MAO-B activities of rats with different $\operatorname{HST}\left(\mathrm{F}_{(2,35)}=6.82, p=0.003\right)$. LHST rats did not show significant differences from control rats $(p=0.31)$. The brain activity of MAO-B (Fig. 2B) was higher in SHST rats than in control rats by $27 \%(p=0.027)$ and higher than in LHST rats by $43 \%(p=0.0014)$. LHST rats did not show significant differences from control rats $(p=0.1)$. The duration of HST negatively correlated with the activities of both $\mathrm{MAO}-\mathrm{A}(\mathrm{R}=$ $-0.721 ; p=0.024)$ and MAO-B $(\mathrm{R}=-0.613 ; p=0.029)$. In addition, brain MAO-A activity positively correlated with the hepatic content of CYP450 $(\mathrm{R}=0.633 ; p=0.027)$. The activities of MAO-A and MAO-B did not significantly differ in control and LHST rats. Brain MAO-B and hepatic CYP450 were not correlated.

Fig. $3 \mathrm{~A}$ shows the differences in the liver MAO-A activity in rats with different $\mathrm{HST}\left(\mathrm{F}_{(2,35)}=9.74, p=0.0004\right)$. The liver activity of MAO-A (Fig. 3A) was higher in SHST rats by $66 \%(p=0.002)$ and in LHST rats by $53 \%(p=0.006)$ than in control rats. LHST rats did not show significant differences from control rats $(p=0.17)$.

Fig. 3B shows the differences in the liver MAO-B activity of the rats with different $\operatorname{HST}\left(\mathrm{F}_{(2,35)}=5.74, p=\right.$ $0.001)$. The liver activity of MAO-B was higher in SHST rats by $43 \%(p=0.006)$ compared to the control and by $51 \%$ compared to LHST rats $(p=0.0034)$. Liver activities of MAOs did not significantly differ in control and LHST rats $(p=0.17)$.

\section{Oxidative stress in brain and in liver in rats with different} HST

MAO activation is associated with $\mathrm{H}_{2} \mathrm{O}_{2}$, which can initiate free-radical oxidation of proteins and lipids (Nagatsu 2004). Fig. 4A shows the differences in the heptane-soluble ketodienes conjugated trienes content in the brain $\left(\mathrm{F}_{(2,35)}=\right.$ $7.88, p=0.001)$ in rats with different HST. This variable was higher in SHST rats by $46 \%(p=0.007)$ and in LHST rats by $57 \%(p=0.006)(p<0.001)$ than in control rats. However, the heptane-soluble ketodiens conjugated trienes content in the brain did not differ significantly in control and LHST rats $(p=0.81)$.

Fig. 4B shows the differences in the brain content of carbonylated proteins in rats with different $\operatorname{HST}\left(\mathrm{F}_{(2,35)}\right.$ $=9.56, p=0.0005)$. A one-way ANOVA showed that the brain content of carbonylated proteins was higher in SHST rats than in the control group by $35 \%(p=0.007)$ and also higher than in LHST rats by $44 \%(p=0.006)$. These variables did not differ significantly in control and LHST rats $(p=0.81)$.

Brain MAO-A activity positively correlated with combined brain concentrations of heptane-soluble ketodienes and conjugated trienes $(\mathrm{R}=0.62 ; p=0.021)$.
Correlations of brain MAO-A with concentrations of carbonylated proteins $(\mathrm{R}=0.49 ; p=0.012)$ and heptanesoluble ketodienes and conjugated trienes $(\mathrm{R}=0.39 ; p=$ 0.018) showed a similar tendency. Brain MAO-B activity positively correlated with the content of carbonylated proteins $(\mathrm{R}=0.57 ; p=0.034)$. These correlations suggest a causative relationship between MAO activity and freeradical oxidation in a brain.

A

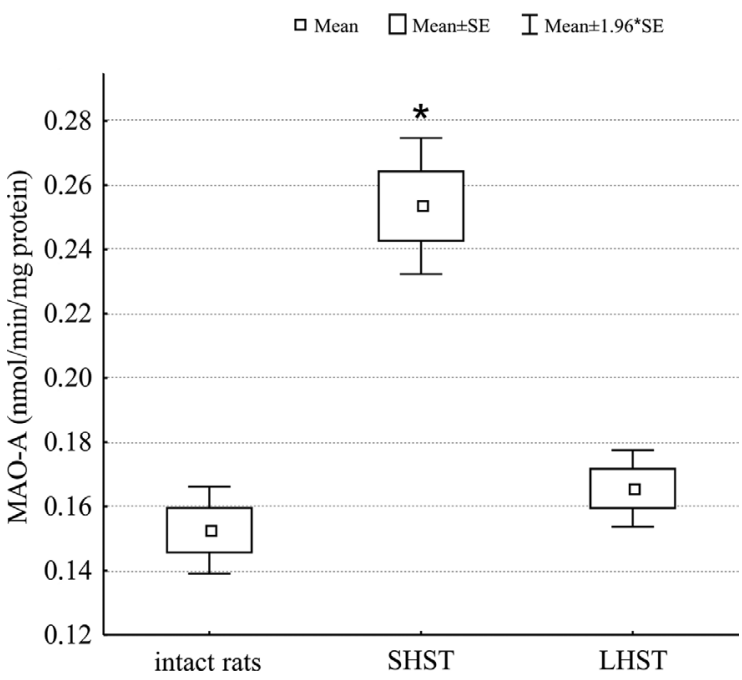

B

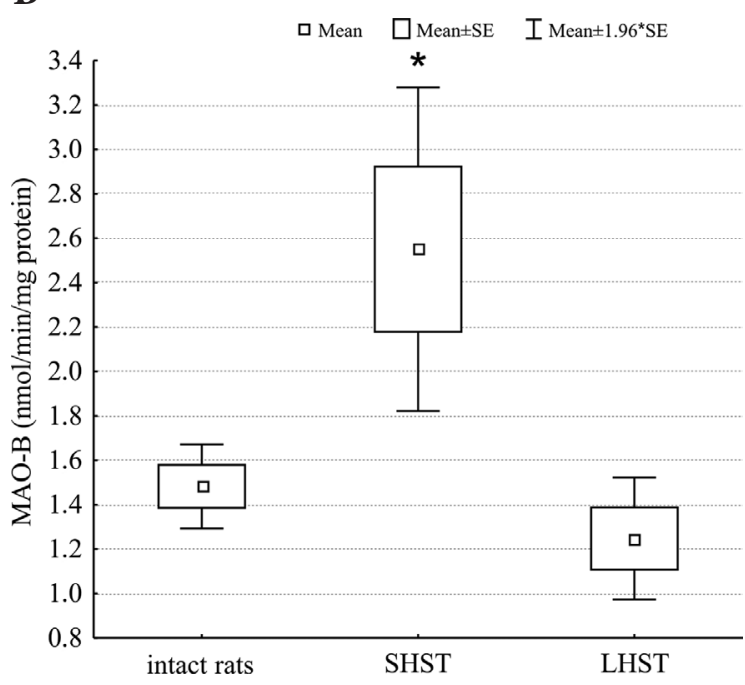

Figure 3. Liver MAOs activity in untreated intact rats and in the hexobarbital treatment subjected rats. A. Liver MAO-A activity was greater in the SHST group than in intact rats $(p=0.001)$ and in the LHST group $(p=0.001)$. B. Liver MAO-B activity was greater in the SHST group than in intact rats $(p=0.01)$ and in the LHST group $(p=0.004) .{ }^{*}$ significant difference from all other groups. 
Figure $5 \mathrm{~A}$ shows the differences in the content of heptanesoluble ketodienes and conjugated trienes of liver tissue in rats with different $\operatorname{HST}\left(\mathrm{F}_{(2,35)}=8.58, p=0.001\right)$. This variable was higher in SHST rats by $46 \%(p=0.006)$ and in LHST rats by $45 \%(p=0.002)$ than in control group. The content of heptane-soluble ketodienes and conjugated trienes of liver tissue did not differ significantly in control and LHST rats $(p=0.71)$.

\section{A}

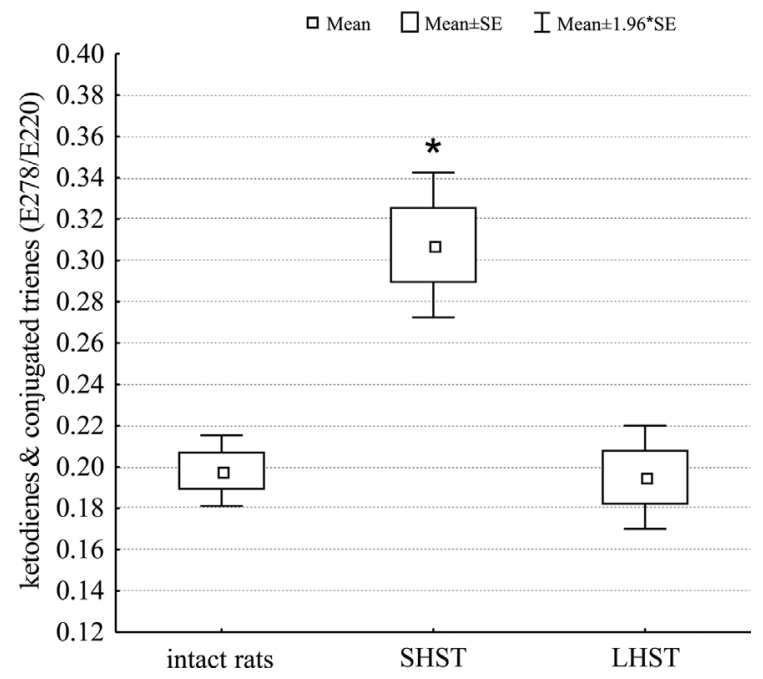

B

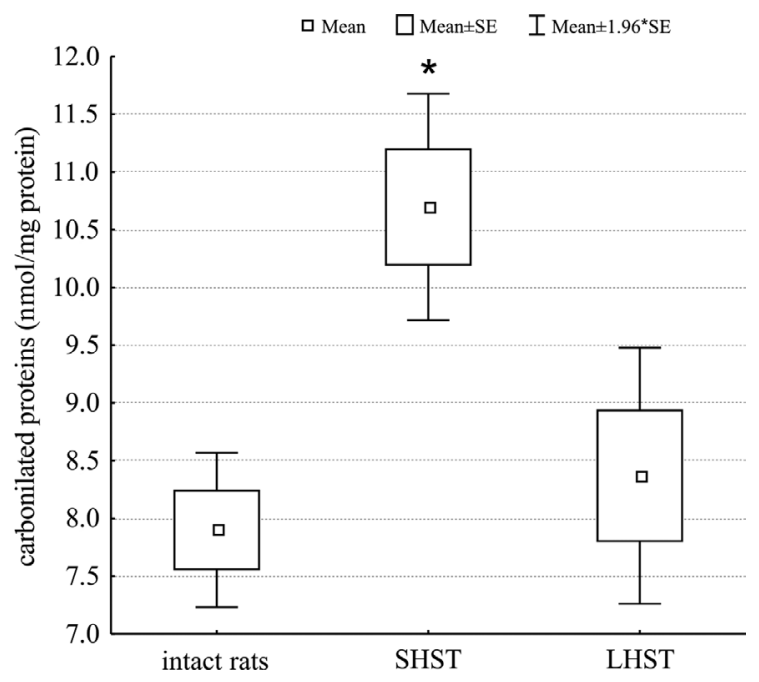

Figure 4. Brain heptane-soluble ketodienes and conjugated trienes and brain carbonylated proteins concentrations in untreated intact rats and in the hexobarbital treatment subjected rats. A. Brain concentration of heptane-soluble ketodienes and conjugated trienes was greater in the SHST group than in intact rats $(p=0.001)$ and in the LHST group $(p=$ 0.001 ). B. Brain concentration of carbonylated proteins was greater in the SHST group than in intact rats $(p=0.001)$ and in the LHST group $(p=0.005) .{ }^{*}$ significant difference from all other groups.
A

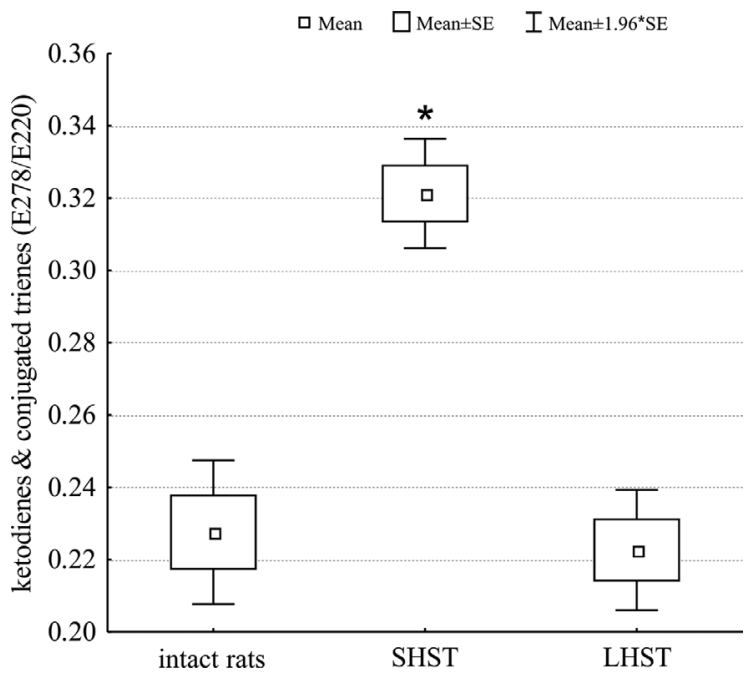

B

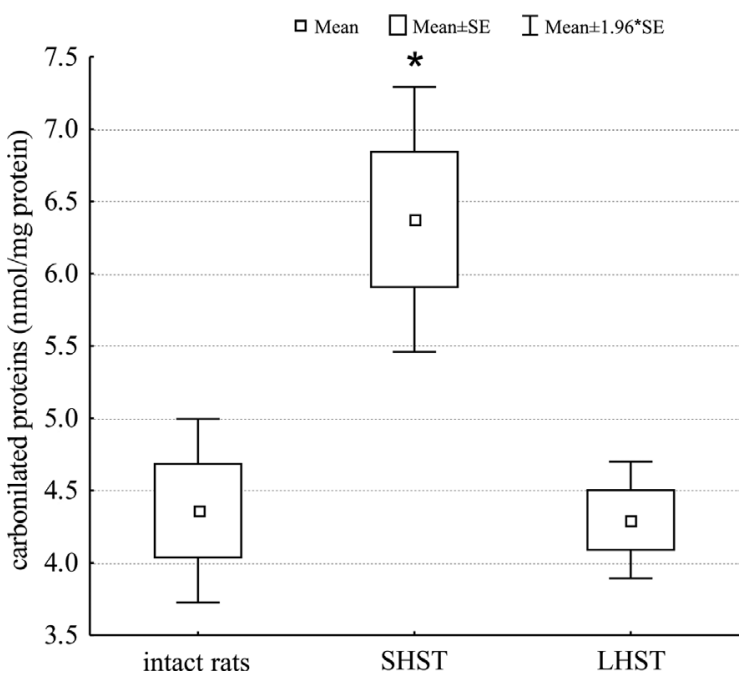

Figure 5. Liver ketodienes, conjugated trienes and carbonylated proteins concentrations in untreated intact rats and in the hexobarbital treatment subjected rats. A. Liver concentration of ketodienes and conjugated trienes was greater in the SHST group than in intact rats $(p=0.001)$ and in the LHST group $(p=0.001)$. B. Liver concentration of carbonylated proteins was greater in the SHST group than in intact rats $(p=0.02)$ and in the LHST group $(p=$ $0.005) .{ }^{*}$ difference from all other groups.

A one-way ANOVA revealed the differences in the brain content of carbonylated proteins $\left(\mathrm{F}_{(2,35)}=11.51, p=0.001\right)$ (Fig. 5B). This variable was $29 \%$ higher in SHST rats than in the control $(p=0.002)$ and by $48 \%$ higher than in LHST rats $(p=0.001)$. These variables did not differ significantly in control and LHST rats. The content of carbonylated proteins of liver tissue did not differ significantly in control and LHST rats $(p=0.81)$. 
Correlations between blood levels of corticosterone and brain and liver MAO activities

One way ANOVA revealed the differences in corticosterone levels in rats with different $\operatorname{HST}\left(\mathrm{F}_{(2,35)}=4.52, p=0.017\right)$. In the SHST group, levels of corticosterone in plasma were lower by $23 \%$ than in the control group $(p=0.028)$ and by $19 \%$ than in the LHST group $(p=0.01)$. Control and LHST rats did not significantly differ $(p=0.9)$.

Concentrations of CYP450 in liver tissue negatively correlated with corticosterone concentrations $(\mathrm{R}=-0.813 ; p=$ $0.015)$. We also found negative correlations of corticosterone concentrations and MAO-A activities in brain $(\mathrm{R}=-0.724$; $p=0.021)$ and liver tissue $(\mathrm{R}=-0.721 ; p=0.024)$. Similar correlations for these variables were found for $(\mathrm{R}=-0.801$; $p=0.012)$ activities of MAO-B for brain and liver tissue $(\mathrm{R}=$ $-0.769 ; p=0.017)$.

Effects of microsomal oxidation inhibitor on corticosterone concentrations, MAO-A and MAO-B activities and $L P$ products concentrations in brain and liver

In rats injected with SKF525 (Table 1), the activities of brain MAO-A and MAO-B were reduced by $34 \%(p<0.001)$ and $37 \%(p<0.001)$, respectively. The activities of liver MAO-A and MAO-B were reduced by $16 \%(p<0.01)$ and by $25 \%$ $(p<0.01)$, respectively. The concentration of LP molecular products in brain tissue was reduced by $16 \%(p<0.01)$, and of carbonylated proteins by $22 \%(p<0.01)$. The concentration of LP molecular products in liver tissue was decreased by $25 \%(p<0.01)$, and of carbonylated proteins by $24 \%$ $(p<0.01)$.

Table 1. Effects of the microsomal oxidation inhibitor, SKF525, on MAO-A and MAO-B activities, free-radical oxidation intensity and corticosterone concentration

\begin{tabular}{clcc}
\hline Substrate & $\begin{array}{c}\text { Control } \\
n=14\end{array}$ & $\begin{array}{c}\text { SKF-525 } \\
(25 \mathrm{mg} / \mathrm{kg}) \\
n=16\end{array}$ \\
\hline \multirow{6}{*}{ brain } & MAO-A & $0.679 \pm 0.06$ & $0.45 \pm 0.15^{\star}$ \\
& MAO-B & $4.00 \pm 1.12$ & $3.10 \pm 1.1^{\star}$ \\
& KD\&CT & $0.2 \pm 0.03$ & $0.16 \pm 0.04^{\star}$ \\
& CP & $10.9 \pm 1.1$ & $6.9 \pm 1.1^{\star}$ \\
\hline \multirow{4}{*}{ liver } & MAO-A & $0.16 \pm 0.02$ & $0.14 \pm 0.01^{\star}$ \\
& MAO-B & $1.51 \pm 0.32$ & $1.29 \pm 0.13^{\star}$ \\
& KD\&CT & $0.21 \pm 0.03$ & $0.18 \pm 0.01^{\star}$ \\
& CP & $5.17 \pm 0.9$ & $3.74 \pm 0.8^{\star}$ \\
\hline & Corticosterone & $661.18 \pm 145.5$ & $762.26 \pm 95.95^{\star}$ \\
\hline
\end{tabular}

Values are means \pm SD. MAO, monoaminoxidase (nmol/min/mg protein); KD\&CT, heptane-soluble ketodienes and conjugated trienes (E278/E220); CP, carbonylated proteins (nmol/mg protein); corticosterone $(\mathrm{nmol} / \mathrm{l}) ;{ }^{*} p<0.01$.
Table 2. Effects of the MAO-A inhibitor clorgyline on MAO-A and MAO-B activities, free-radical oxidation intensity and corticosterone concentration

\begin{tabular}{|c|c|c|c|}
\hline & Substrate & $\begin{array}{c}\text { Control } \\
n=11\end{array}$ & $\begin{array}{c}\text { Clorgyline } \\
(1 \mathrm{mg} / \mathrm{kg}) \\
n=10\end{array}$ \\
\hline \multirow{4}{*}{ brain } & MAO-A & $0.68 \pm 0.06$ & $0.29 \pm 0.053^{*}$ \\
\hline & MAO-B & $4.00 \pm 1.12$ & $3.77 \pm 0.47^{\star}$ \\
\hline & KD\&CT & $0.2 \pm 0.03$ & $0.16 \pm 0.04^{*}$ \\
\hline & $\mathrm{CP}$ & $10.1 \pm 1.1$ & $7.00 \pm 0.6^{*}$ \\
\hline \multirow{5}{*}{ liver } & MAO-A & $0.15 \pm 0.02$ & $0.12 \pm 0.01^{\star}$ \\
\hline & MAO-B & $1.48 \pm 0.32$ & $1.66 \pm 0.57^{\star}$ \\
\hline & KD\&CT & $0.23 \pm 0.03$ & $0.18 \pm 0.02^{\star}$ \\
\hline & $\mathrm{CP}$ & $5.00 \pm 0.9$ & $2.9 \pm 1.3^{\star}$ \\
\hline & Corticosterone & $624.68 \pm 173.1$ & $665.24 \pm 96.75^{\star}$ \\
\hline
\end{tabular}

$\overline{\text { Values are means } \pm \mathrm{SD} ;{ }^{*} p<0.01 \text {. (For abbreviations, see Table } 1 \text { ). }}$

Effects of MAO-A and MAO-B selective inhibitors on concentrations of LP molecular products and carbonylated proteins in brain and liver

Clorgyline reduced brain concentration of LP molecular products (Table 2$)$ by $19 \%(p<0.01)$ and liver concentration of LP molecular products by $21 \%(p<0.01)$. In rats receiving clorgyline, concentrations of carbonylated proteins were reduced by $12 \%(p<0.01)$ in the brain and by $33 \%(p<0.01)$ in the liver. The utilized dose of clorgyline did not induce any significant changes in concentrations of CYP450 (control, $1313.25 \pm 283.93 \mathrm{ng} / \mathrm{mg}$ protein; clorgyline, $1294.63 \pm$ $69.63 \mathrm{ng} / \mathrm{mg}$ protein).

In rats receiving selegeline (Table 3 ), concentrations of LP molecular products were decreased by $27 \%$ in the brain

Table 3. Effects of the MAO-B inhibitor selegeline on MAO-A and $\mathrm{MAO}-\mathrm{B}$ activities, free-radical oxidation intensity and corticosterone concentration

\begin{tabular}{clcc}
\hline Substrate & $\begin{array}{c}\text { Control } \\
n=11\end{array}$ & $\begin{array}{c}\text { Selegeline } \\
(1 \mathrm{mgh} / \mathrm{kg}) \\
n=10\end{array}$ \\
\hline \multirow{6}{*}{ brain } & MAO-A & $0.67 \pm 0.06$ & $0.68 \pm 0.045$ \\
& MAO-B & $4.48 \pm 1.12$ & $3.00 \pm 1.27^{*}$ \\
& KD\&CT & $0.22 \pm 0.03$ & $0.14 \pm 0.03^{*}$ \\
& CP & $7.90 \pm 1.1$ & $6.78 \pm 1.9^{*}$ \\
\hline \multirow{4}{*}{ liver } & MAO-A & $0.15 \pm 0.02$ & $0.12 \pm 0.01^{*}$ \\
& MAO-B & $1.48 \pm 0.32$ & $0.96 \pm 0.57^{*}$ \\
& KD\&CT & $0.21 \pm 0.03$ & $0.18 \pm 0.03^{*}$ \\
& CP & $4.41 \pm 0.9$ & $3.10 \pm 1.0^{*}$ \\
\hline & Corticosterone & $698.48 \pm 85.7$ & $667.46 \pm 67.81^{*}$ \\
\hline
\end{tabular}

Values are means $\pm \mathrm{SD} ;{ }^{*} p<0.01$. (For abbreviations, see Table 1 ). 
$(p<0.01)$ and by $19 \%$ in the liver $(p<0.01)$. Concentrations of carbonylated proteins were decreased by $15 \%$ in the brain $(p<0.01)$ and by $32 \%$ in the liver $(p<0.005)$. The utilized dose of selegeline did not induce any significant changes in concentrations of CYP450 (control, $1313.25 \pm 283.93 \mathrm{ng} / \mathrm{mg}$ protein; selegeline, $1285.83 \pm 69.81 \mathrm{ng} / \mathrm{mg}$ protein).

\section{Discussion}

It has been shown in previous data that MAO activity in different brain regions are correlated with a microsomal oxidation phenotype (Tseilikman et al. 2016). SHST rats had a higher content of microsomal CYP than LHST rats. Whole brain MAO-A and MAO-B activities, serotonin and carbonylated protein levels were higher in SHST than in LHST rats. MAO-A and MAO-B activities were higher in the brain cortex of SHST rats; MAO-A activity was higher only in the hypothalamus and medulla of LHST. The same brain regions of LHST rats had higher concentrations of carbonylated proteins and lipid peroxidation products than in SHST rats. However, the previous research did not consider the differences between control and HST rats. Moreover, the previous studies did not consider differences in MAO activities in the liver of rats with a different microsomal oxidation phenotype. The data obtained in this study, using the microsomal oxidation inhibitor, SKF525, and using animals with different duration of hexobarbital sleep, has shown that increased intensity of microsomal oxidation might be associated with increased MAO activity. These data should be discussed taking into account reports of interactions of biogenic amine neurotransmitters with CYP450-dependent monooxygenases (Wójcikowski and Daniel 2011). Central dopaminergic, noradrenergic and serotoninergic systems regulate activity of several CYP450-dependent monooxygenases in the liver by stimulating production of pineal hormones. These hormones stimulate liver nuclear and cytoplasmic receptors regulating CYP genes (Wójcikowski and Daniel 2011). Importantly, biogenic amines in the central nervous system are negatively regulated by CYP isoforms. For example, local administration of the neurotoxin, DSP-4, which affects noradrenergic terminals, simultaneously decreases norepinephrine, dopamine and serotonin in mid-hypothalamus and increases CYP2C11, CYP3A and CYP2A isoform expression (Bromek et al. 2013). On the other hand, some CYP450 isoforms are involved in biosynthesis of biogenic amines. For instance, the recent Haduch report characterized the contribution of the CYP450 isoform, CYP2D6, to the transformation of 5-methoxytryptamine into serotonin (Haduch et al. 2013).

It is known that $\mathrm{MAO}$ is a component of a system providing a balance of biogenic amines in the brain. We observed the reduction of MAO activity along with the reduction oxidative stress in brain and liver. We believe MAO, due to the inactivation of biogenic amines, may stimulate CYP450 activity. This hypothesis is supported by current data obtained from animals with different HST. In SHST rats, which have a higher intensity of microsomal oxidation, the activities of MAO-A and MAO-B, in both the brain and liver, were higher than in control and LHST rats. Also, SHST rats had higher levels of LP products and carbonylated proteins. SKF525 decreased LP products and carbonylated proteins in the brain and liver tissue. Apparently, this inhibitor of microsomal oxidation restricted oxidative stress by reducing MAO activities. It is also possible that SKF525 restricted oxidative stress by directly inhibiting microsomal oxidation. Since superoxide is known to be a by-product of microsomal oxidation, inducers of various CYP450 isoforms can potentiate free-radical processes (Caro and Cederbaum 2006).

The data obtained with the use of the microsomal oxidation inhibitor, SKF525, are consistent with the results of correlation analysis of animals with different HST. Effects of SKF525 are in good agreement with HST and MAO activities in the brain and liver as well as with concentrations of LP molecular products and carbonylated proteins in the brain. In addition, the results of inhibiting microsomal oxidation explain the positive correlations of these indices with the content of CYP450 in hepatic microsomes. Positive correlations of brain heptane-soluble ketodienes and conjugated trienes with the brain activity of MAO-A suggest involvement of MAO-A in the LP activation. Our data can explain the contribution of increased MAO activity to maintenance of the increased intensity of microsomal oxidation. At the same time, the experiment with the microsomal oxidation inhibitor, SKF525, indicated the importance of CYP450 for maintaining increased activities of MAO-A and MAO-B.

The contribution of microsomal oxidation to regulation of MAO activity may be determined by metabolism of steroid hormones via CYP450-dependent monoxygenases. Specifically, glucocorticoids are metabolically inactivated by 6- $\beta$ hydroxylation in the liver (Quattrochi et al. 2001). Glucocorticoids are known to be regulators of MAO activity. However, the data available on this issue are inconsistent. On the one hand, glucocorticoids have been reported to stimulate expression of MAO-A and MAO-B by increasing expression of the transcriptional factor, KLF-11 (Duncan et al. 2012; Ou et al. 2019). In addition, in chronic stress, longterm increases in glucocorticoid concentration are associated with MAO activation (Grunewald et al. 2012). On the other hand, both administration of dexamethasone (Cvijić et al. 1995) and acute stress (Soliman et al. 2012) decrease MAO activity. The glucocorticoid regulation of MAO activity is most likely to be different in the presence and absence of stress. The corticosterone level was lower in SHST rats than in control or LHST rats; under these conditions, SKF525 increased the corticosterone level. In the absence of stress, glucocorticoid concentrations would be expected to negatively correlate with MAO-A and MAO-B activities. 
In the brain, MAO-dependent oxidative stress is involved in the induction of neuronal apoptosis and development of neurodegeneration, as, for example, in the case of Parkinson's disease (Nagatsu, 2004). Also, increased MAO may contribute to behavioral disorders (Duncan 2012).

Increased cerebral MAO activity has been associated with anxiety-depressive disorders (Volchegorskii et al. 2004). Earlier, behavioral disorders homologous to human melancholic depression were modeled in rats using four restraint sessions one hour each with 72-hour intervals between the restraint sessions (Volchegorskii et al. 2004). In that study, rats with increased MAO-B activity showed decreased locomotor activity and increased frequency of anxiogenic defecation. Using this model of anxiogenic stress, we observed that anxiety-depressive disorders were associated with increased cerebral lipid peroxidation, which could be limited with the MAO-B inhibitor, selegeline (Tseilikman et al. 2009). Cerebral MAO is involved in the regulation of behavioral activity due to the MAO contribution to regulation of neurotransmitters. Importantly, CYP450-dependent monooxygenases play a key role in biotransformation of MAO-A and MAO-B inhibitors, which are used to treat psychiatric and neurological diseases (Nagatsu 2004). For this reason, future studies of CYP450 contribution to behavioral regulation in depressive disorders, alcohol addiction, and stress situations seem promising. In these conditions, glucocorticoids may play the role of mediator between CYP450 and MAO.

In conclusion, the results of this study show that microsomal oxidation regulates the brain and liver activities of MAO, which correlate with the microsomal oxidation phenotype. We have observed that the rats with higher hepatic content of cytochrome $\mathrm{P} 450$ have higher activities of MAO-A and $\mathrm{MAO}-\mathrm{B}$ in the brain than rats with lower microsomal oxidation. These conclusions are substantiated by using a microsomal oxidation inhibitor and specific MAO-A and MAO-B inhibitors. The microsomal oxidation regulation of MAO activities may be based on CYP450-dependent metabolism of MAO endocrine regulators, such as glucocorticoids.

Acknowledgements. The South Ural State University is grateful for financial support of the Ministry of Education and Science of the Russian Federation (Grant \#17.7255.2017/8.9) and the Russian Science Foundation (Grant \#17-15-013418).

\section{Conflict of interests. None declared.}

Statement of author contribution. All authors participated in the design, interpretation of the studies and analysis of the data and review of the manuscript; D.A.K. isolated microsomes and measured cytochrome P450; M.V.K. and M.V.V. measured activities of cerebral MAO-A and MAO-B; O.B.T. performed the hexobarbital sleep test, administered SKF525, clorgyline and selegeline. M.N.S. collected and processes blood plasma, and isolated brain; M.S.L. and S.S.L. measured LP molecular products and brain carbonyls;
V.E.T. designed the study and drafted the manuscript; E.B.M. and H.F.D. expanded and edited the manuscript and assisted with data interpretation.

\section{References}

Abell C. W., Kwan S. W. (2001): Molecular characterization of monoamine oxidase A and B. Prog. Nucleic Acid Mol. Biol. $65,129-156$ https://doi.org/10.1016/S0079-6603(00)65004-3

Bromek E., Haduch A., Gołembiowska K., Daniel W. A. (2011): Cytochrome P450 mediates dopamine formation in the brain in vivo Cytochrome $\mathrm{P} 450$ mediates dopamine formation in the brain in vivo. J. Neurochem. 118, 806-815 https://doi.org/10.1111/j.1471-4159.2011.07339.x

Brunner H. G., Nelen M., Breakfield X. O., Ropers H. H., Van Oost B. A. (1993): Abnormal behavior associated with a point muta $\neg$ tion in the structural gene for monoamine oxidase A. Science 262, 578-580 https://doi.org/10.1126/science.8211186

Caro A. A., Cederbaum A. I. (2006): Role of cytochrome P450 in phospholipase A2- and arachidonic acid-mediated cytotoxicity. Free Radic. Biol. Med. 40, 364-375 https://doi.org/10.1016/j.freeradbiomed.2005.10.044

Chen K., Shih J. C. (1998): Monoamine oxidase A and B: structure, function, and behavior. Adv. Pharmacol. 42, 292-296 https://doi.org/10.1016/S1054-3589(08)60747-4

Cherala G., Shapiro B. H., D'mello A. P. (2007): Effect of perinatal low protein diets on the ontogeny of select hepatic cytochrome p450 enzymes and cytochrome p450 reductase in the rat. Drug Metab. Dispos. 35, 1057-1063 https://doi.org/10.1124/dmd.106.013748

Choi Y.H., Lee M. G. (2006): Effects of enzyme inducers and inhibitors on the pharmacokinetics of metformin in rats: involvement of CYP2C11, 2D 1 and 3A1/2 for the metabolism of metformin. Br. J. Pharmacol. 149, 424-430 https://doi.org/10.1038/sj.bjp.0706875

Coville P. M., Telford J. M. (1970): The effect of thyroid hormones on the action of some centrally acting drugs. Br. J. Pharmacol. 40, 747-758 https://doi.org/10.1111/j.1476-5381.1970.tb10652.x

Cvijić G., Radojicić R., Djordjević J., Davidović V. (1995): The effect of glucocorticoids on the activity of monoamine oxidase, copper-zinc superoxide dismutase and catalase in the rat hypothalamus. Funct. Neurol. 10, 175-181

Duncan J., Johnson S., Ou X. M. (2012): Monoamine oxidases in major depressive disorder and alcoholism. Drug Discov. Ther. 6, 112-122 https://doi.org/10.5582/ddt.2012.v6.3.112

Ekstedt B., Oreland L. (1976): Effect of lipid-depletion on the different forms of monoamine oxidase in rat liver mitochondria. Biochem. Pharmacol. 25, 119-124 https://doi.org/10.1016/0006-2952(76)90277-X

Furlong R. A., Ho L., Rubinsztein J. S., Walsh C., Paykel E. S., Rubinszlein D. C. (1999): Analysis of the monoamine oxidase A (MAO A) gene in bipolar affeclive disorder by association studies, mcta-analysis, and sequencing of the promoter. Am. J. Med. Genet. 88, 398-406 
https://doi.org/10.1002/(SICI)1096-8628(19990820)88:4<398::AID-AJMG18>3.0.CO;2-Y

Glover V., Sandler M., Owen F., Riley G. J. (1977): Dopamine is a monoamine oxidase B substrate in man. Nature 265, 80-81 https://doi.org/10.1038/265080a 0

Grunewald M., Johnson S., Lu D., Wang Z., Lomberk G., Albert P. R., Stockmeier C. A., Meyer J. H., Urrutia R., Miczek K. A. et al. (2012): Mechanistic role for a novel glucocorticoid-KLF11 (TIEG2) protein pathway in stress-induced monoamine oxidase A expression. J. Biol. Chem. 287, 24195-206 https://doi.org/10.1074/jbc.M112.373936

Haduch A., Bromek E., Sadakierska-Chudy A., Wójcikowski J., Daniel W. A. (2013): The catalytic competence of cytochrome P450 in the synthesis of serotonin from 5-methoxytryptamine in the brain: an in vitro study. Pharmacol. Res. 67, 53-59 https://doi.org/10.1016/j.phrs.2012.10.009

Miura H., Naoi M., Nakahara D., Ohta T., Nagatsu T. (1993): Changes in monoamine levels in mouse brain elicited by forcedstress, and the protective effect of a new monoamine inhibitor, RS-8359. J. Neural Trans. 94, 175-187 https://doi.org/10.1007/BF01277023

Nagatsu T. (2004): Progress in monoamine oxidase (MAO) research in relation to genetic engineering. Neurotoxicology 25, 11-20 https://doi.org/10.1016/S0161-813X(03)00085-8

Ou X. M., Stockmeier C. A., Meltzer H. Y., Overholser J. C., Jurjus G. J., Dieter L., Chen K., Lu D., Johnson C., Youdim M. B., Austin M. C., Luo J., Sawa A., May W., Shih J. C. (2010): A novel role for glyceraldehyde-3-phosphate dehydrogenase and monoamine oxidase B cascade in ethanol-induced cellular damage. Biol. Psychiatry 67, 855-863 https://doi.org/10.1016/j.biopsych.2009.10.032

Omura T., Sato R. (1964): The carbon monoxide binding pigment of liver microsome. Evidence of haemoprotein nature. J. Biol. Chem. 239, 2370-2378

Pappas J. B., Franklin M. R. (1993): Hepatic clotrimazole concentra $\neg$ tions and hepatic drug metabolizing enzyme activities in adult male Sprague-Dawley rats. Toxicology 80, 27-35 https://doi.org/10.1016/0300-483X(93)90074-3

Quattrochi L. C., Guzelian P. S. (2001): Cyp3A regulation: from pharmacology to nuclear receptors. Drug Metab. Dispos. 29, 615-622

Satav J. G., Katyare S. S. (2004): Effect of streptozotocin-induced diabetes on oxidative energy metabolism in rat liver mito $\neg$ chondria-A comparative study of early and late effects. Indian J. Clin. Biochem. 19, 23-31

https://doi.org/10.1007/BF02894253

Spina E., Trifirò G., Caraci F. (2012): Clinically significant drug interactions with newer antidepressants. CNS Drugs 26, 39-67 https://doi.org/10.2165/11594710-000000000-00000

Soliman A., Udemgba C., Fan I., Xu X., Miler L., Rusjan P., Houle S., Wilson A. A., Pruessner J., Ou X. M., Meyer J. H. (2012): Convergent effects of acute stress and glucocorticoid exposure upon MAO-A in human. J. Neurosci. 32, 17120-17127 https://doi.org/10.1523/JNEUROSCI.2091-12.2012

Tipton K. F., Youdim M. B. H., Barwell C. J., Callingham B. A., Lyles G. A. (1992): Amine oxidase: function and dysfunction. J. Neural Trans. 41, 1-57

Tipton K. F., Davey G., Motherway M. (2006): Monoamine oxidase assays. Curr. Protoc. Toxicol. 4, 4.21 https://doi.org/10.1002/0471141755.tx0421s30

Tseilikman V. E., Sinitsky A. I., Poyarkov K. A., Vojdaev E. V. (2009): Effect of deprenyl on free radical oxidation in rat brain during immobilization stress. Bull. Exp. Biol. Med. 148, 856-858 http://dx.doi.org/10.1007/s10517-010-0835-1 https://doi.org/10.1007/s10517-010-0835-1

Tseilikman V. E., Kozochkin D. A., Manukhina E. B., Downey H. F., Tseilikman O. B., Misharina M. E., Nikitina A. A., Komelkova M. V., Lapshin M. S., Kondashevskaya M. V. et al. (2016): Duration of hexobarbital-induced sleep and monoamine oxidase activities in rat brain: Focus on the behavioral activity and on the free-radical oxidation. Gen. Physiol. Biophys. 35, 175-183 https://doi.org/10.4149/gpb_2015039

Volchegorskii I. A., Tseilikman V. E., Smirnov D. S., Ship S. A., Borisenkov A. V. (2004): Decreases in glucocorticoid sensitiv $\neg$ ity as a factor of stress-producing changes in the activity of monoamine oxidase, lipid peroxidation, and behavior in rats. Neurosci. Behav. Physiol. 34, 697-701 https://doi.org/10.1023/B:NEAB.0000036010.90414.d9

Wójcikowski J., Haduch A., Daniel W. A. (2012): Effect of classic and atypical neuroleptics on cytochrome P450 3A (CYP3A) in rat liver. Pharmacol. Rep. 64, 1411-1418 https://doi.org/10.1016/S1734-1140(12)70938-6

Received: August 5, 2016

Final version accepted: March 7, 2017

First published online: June 27, 2017 